\title{
Research on Urban Rainfall Runoff Pollution Prediction Model Based on Feature Fusion
}

\author{
Junping Yao $\mathbb{D}^{1}$ and Tianle Sun $\mathbb{D}^{2}$ \\ ${ }^{1}$ School of Electronic and Information Engineering, Chongqing Radio \& TV University, Chongqing, China \\ ${ }^{2}$ College of Horticulture Sichuan Agricultural University, Chengdu, China \\ Correspondence should be addressed to Junping Yao; yao_junping@126.com and Tianle Sun; suntianle2002@163.com
}

Received 20 August 2020; Revised 19 October 2020; Accepted 9 November 2020; Published 20 November 2020

Academic Editor: Jia-Bao Liu

Copyright $\odot 2020$ Junping Yao and Tianle Sun. This is an open access article distributed under the Creative Commons Attribution License, which permits unrestricted use, distribution, and reproduction in any medium, provided the original work is properly cited.

\begin{abstract}
In this paper, a rainfall runoff pollution prediction method based on grey neural network algorithm is proposed in consideration of the current situation that the accuracy of research results related to rainfall runoff pollution prediction needs to be improved. Meanwhile, the characteristics of rainfall runoff pollution are analyzed from the perspectives of the main sources of rainfall runoff pollution, the types of rainfall runoff pollution, and the initial erosion. The neural network algorithm is optimized and trained according to the sample data to obtain the sample features; the sample data are predicted according to the extracted sample features, and the prediction model is generated by using the feature fusion technology for two groups of prediction results to generate the prediction model and realize the water drop prediction. The pollution concentration of runoff was obtained by the exponential function method. The experimental results show that the predicted values of discharge and pollution concentration are well fitted with the actual values, indicating that the proposed method has high accuracy and feasibility. Finally, from the viewpoint of non-engineering measures and engineering measures, the suggestions for treating runoff pollution and relevant supports for ecological environment protection are given.
\end{abstract}

\section{Introduction}

As one of the natural disasters that threaten the public life and property safety, the flood disaster caused by rainfall is generating more and more serious harms in today's society with various types of disasters [1]. Therefore, it is of great guiding role in ecological management by reducing the pollution caused by flooding and erosion through improving the accuracy of rainfall runoff pollution prediction [2].

Due to the accelerated urbanization in China, the proportion of the total area of permeable ground is getting smaller. As a result, the emergent and impactful pollutions caused by rainfall runoff have already become the main source of ecological environmental pollutions [3]. Due to the large-scale pollutants contained in rainfall runoff, its initial runoff load is much heavier than that of domestic sewage [4]. Thus, the prediction and treatment of rainfall runoff pollution is an urgent problem to be solved in ecological environment management, which has aroused extensive attentions and received in-depth researches by relevant experts and scholars [5].

By combining with strengths of relevant research achievements, the method of rainfall runoff prediction based on grey neural network algorithm is proposed so as to effectively enhance the prediction accuracy. At the same time, the feasibility of this method was verified to better improve the prediction of rainfall runoff pollution and treatment of environmental containment.

\section{Rainfall Runoff Pollution Prediction Based on Grey Neural Network Algorithm}

2.1. Characteristics of Rainfall Runoff Pollution Extract. The urban runoff, as being classified according to certain principles, belongs to non-point source pollution [6]. Strictly speaking, rainfall runoff has the characteristics of both surface source and point source. Among them, the surface source characteristic is mainly embodied in the following 
aspects: the pollutants accumulate on the surface on sunny days but will be discharged to different places with the surface runoff on rainy days, so there are intermittent emission characteristics of surface source [7]. In regard to the point source characteristic, the pollutants are discharged to the storage water body, so there are the characteristics of centralized discharge [8].

2.1.1. Main Source of Rainfall Runoff Pollution. Surface pollution is the most important among the different sources of rainfall runoff pollution. The following analysis focuses on the accumulation and erosion in road surface pollution [9].

The total content of various pollutants on the surface, during the process of pollutant accumulation, will be affected by atmospheric dustfall, land use, and traffic [10]. In addition to particulates, dustfall also contains many types of pollutants; the influence of land use on surface pollution is diverse; traffic has a great impact on the cumulative rate of pollutions in cities or adjacent road sections, such as the toxic metal substances, especially lead, produced by friction between the ground and vehicle exhaust as well as auto parts. Road pollutants are also correlated with the type of urban industry and the surrounding geological conditions. The particles present in the rubbish on the road are generally transmitted from nearby soil and industrial dust by air. In summary, the consideration shall be given to the above factors while analyzing the accumulation of road surface pollution [11].

During the rainfall, the surface pollutants are eroded and there is correlation in the nature of pollutants. For example, the reactions of washing soluble and insoluble materials are different [12]. Besides, the water permeability of road surface will also have a certain impact on the erosion of pollutants. Furthermore, the differences in the depth and flow velocity of surface runoff in different regions also directly affect the performance of pollutant erosion.

On the impervious area, some soluble pollutants will be eroded first by rainfall. At the beginning of rainfall, it only moistens the road surface and the pollutants [13]. As a result, the loose pollutants will be splashed by raindrops, thereby enhancing the dissolution efficiency. Gradually, sufficient rainfall wets the ground and forms runoff, so that the lowlying places are filled and the soluble pollutants on the road surface are dissolved, especially the location with accumulated pollutants, such as street side ditch and roof collecting pipe [14]. The continuous formation and flow of surface runoff will take away large-scale soluble pollutants, while the insoluble pollutants will only move as soon as the local surface runoff reaches a certain speed. Once the flow rate exceeds the initial speed, the solid particles on the road surface begin to move, and so do the contaminants adsorbed on these particles. There are some differences in the movement due to the different sizes of the particles, but these pollutants will eventually flow into the gutter inlet with the rainfall runoff and gradually move downward through the pipe network. In the permeable area, some of the soluble and insoluble pollutants will adhere to the surface particles due to the upward penetration of rainwater, while others may move into the groundwater along with the seepage, so that groundwater pollution is formed. When the surface runoff occurs as the rainfall intensity exceeds the soil infiltration performance, various soluble and insoluble pollutants entrained during the rainfall runoff will flow into the rainwater well [15].

2.1.2. Types of Rainfall Runoff Pollution. At present, most of the domestic and overseas researches pay attention to the pollutants such as suspended sediments, bacteria, and some toxic pollutants.

The rainfall runoff carries a lot of sediments. Generally speaking, the soil erosion in the old city is more serious; the mixed sediments in urban area mainly come from the various substances generated by the rust of vehicles, the wastes generated by motor vehicles, and the smoke exhausted from household chimneys, especially in industrial and commercial areas, highways, and some construction sites. Rainfall runoff contains many nutrients, which, after flowing to rivers or lakes and then into large estuaries and oceans, will lead to eutrophication of water bodies and damage the ecological environment. The runoff contains large scale of various organic substances, including domestic garbage and wastes, which will consume large amounts of oxygen in the water once starting to decompose. Therefore, after the rainstorm, the oxygen present in lakes or rivers will be consumed up, of which the oxygen consumption of runoff from the old city is the highest. Bacteria mainly come from animals and sewer overflows. The toxic substances present in rainfall runoff include heavy metals, pesticides, and polycyclic aromatic hydrocarbons, where the most typical pollutants of heavy metals derive from motor vehicles.

2.1.3. Initial Erosion. In rainfall runoff, the initial erosion refers to the occurrence of runoff since the start of rainfall, during which the pollutant content is the highest with largescale pollutants flowing into the receiving water body. As can be observed from relevant researches, the total contents of pollutants during initial rainfall runoff are affected by indicators such as confluence area and rainfall intensity. Therefore, the research is complex and the concept of initial rainfall erosion remains to be determined.

2.2. Precipitation Prediction. Considering the close relationship between precipitation and runoff pollution, the grey neural network method is adopted to accurately predict rainwater runoff pollution. At present, neural network and grey system prediction models are widely adopted in various aspects. As can be concluded from analyzing the advantages and disadvantages of the grey waveform method as well as the neural network, the grey prediction method is more suitable for small data volume prediction because it can constantly approach the complex nonlinear functions. However, there will be predication errors and the prediction accuracy is low when applying the grey prediction method to the system in poor stability. Compared with the grey prediction method, artificial neural network is better in nonlinear mapping, which can not only properly predict various mutation data through learning but also predict some special cases. The disadvantage is that the prediction 
accuracy of neural network is relatively low because the largescale representative information data are needed for practical training during prediction, but there is no enough data in practical application [16]. For this reason, to organically combine the neural network with grey prediction and realize complementarity will help overcome the limitations of the single prediction model and prevent the loss of effective information, so that the prediction accuracy of rainfall runoff pollution will be promoted.

With respect to the model of combining the grey model NGM $(1,1, \mathrm{k})$ with neural network WNN, it means to effectively integrate grey system theory with $\mathrm{WNN}$ to gain more useful information, design and construct a grey neural network prediction model, and then improve the prediction accuracy. The main combination modes are divided into serial combination, parallel combination, grey compensation combination, and deep fusion. In the serial combination, the output result of one side is regarded as the input data of the other side, where the output result of the latter is the final prediction result; the parallel combination means to separately predict the two sides, so as to obtain the combined prediction result by weighing the weight values, which is also the final result of prediction model; the grey compensation combination is to acquire the mapping correlation between grey algorithm residuals and grey prediction method after conducting iterative training on the neural network, and then correct the grey prediction result according to the compensation value of neural network algorithm; in deep fusion, the two sides are fused into a grey waveform-WNN to achieve mutual complementarity in the prediction.

The parallel combination mode is selected after in-depth analysis, as shown in Figure 1. The optimal combined prediction model is constructed by combining the improved grey algorithm with the neural network prediction model.

The main ideas for designing and constructing the combined feature extraction model are as follows:

(1) The ant colony algorithm is applied to optimize the neural network algorithm and conduct training based on the sample data, so that the first group of eigenvalues is obtained and set to $Y_{1}=\left\{y_{1 i} \mid t, n q i h={ }_{1} x, 7 \ldots C, ; N\right\}$, and the error set is defined as $E_{1}=\left\{e_{1 i} \mid t, n q i h={ }_{1} x, 7 \ldots C, ; N\right\}$.

(2) The sample data is predicted according to the improved NGM $(1,1, \mathrm{k})$ method, so that the second group of eigenvalues is obtained and set to $Y_{2}=\left\{y_{2 i} \mid t, n q i h={ }_{1} x, 7 \ldots C, ; N\right\}$, and the error set is defined as $E_{2}=\left\{e_{2 i} \mid t, n q i h={ }_{1} x, 7 \ldots C, ; N\right\}$.

(3) The linear combination operations are performed on the two groups of feature extraction results (1) and (2) through feature fusion, so that a model is generated.

Among them, the feature fusion is calculated as follows. After that, the optimal combination method is used to solve the weight coefficients of each feature extraction method based on the basic principle of minimum combination error value in the process of extracting features. At the same time, the weight coefficients of each single feature extraction method are fixed values in each prediction period.

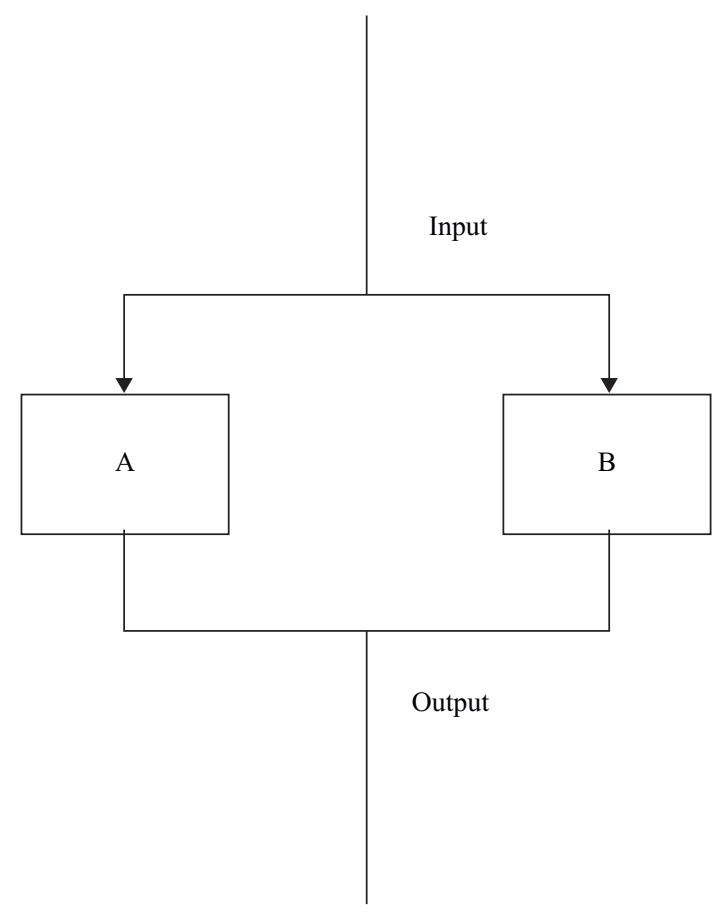

FIGURE 1: Schematic diagram of parallel combination mode.

Assume that there are currently $m$ ways to implement combined prediction, in which each prediction method has a weight coefficient of $k_{1}, \ldots, k_{i}, \ldots k_{m}$ and satisfies $k_{1}, \ldots, k_{i}, \ldots, k_{m}$. Suppose that $e_{i t}$ represents the error of the $i$-th mode in the time bucket $t$, and there are a total of $n$ time buckets; then, the total error values of the combined prediction time buckets are

$$
\begin{aligned}
e_{t}= & k_{1} e_{1 t}+\cdots+k_{i} e_{i t}+\cdots+k_{m} e_{m t} \\
= & k_{1} e_{1 t}+\cdots+k_{i} e_{i t}+\cdots+k_{m-1} e_{(m-1) t} \\
& +\left(1-k_{1}-\cdots-k_{m-1}\right) e_{m t} \\
= & k_{1}\left(e_{1 t}-e_{m t}\right)+\cdots+k_{2}\left(e_{2 t}-e_{m t}\right)+\cdots+k_{i}\left(e_{i t}-e_{m t}\right) \\
& +\cdots+k_{m-1}\left(e_{(m-1) t}-e_{m t}\right)+e_{m t} .
\end{aligned}
$$

Let

$$
f_{i t}=e_{i t}-e_{m t} \mid(i=1, \ldots, m-1) .
$$

Then, the equation for calculating errors is

$$
e_{t}=k_{1} f_{1 t}+\cdots+k_{i} f_{i t}+\cdots+k_{m-1} f_{(m-1) t}+f_{m t} \text {. }
$$

According to the above analysis, the prediction target is to minimize the sum of squared errors, that is, obtaining $k_{1}, k_{i}, \ldots, k_{m}$ to minimize equation (4).

$$
Q=\sum_{i=1}^{n} e_{2 t}=\sum_{i=1}^{n}\left(k_{1} f_{1 t}+\cdots+k_{i} f_{i t}+\cdots+k_{m-1} f_{(m-1) t}+f_{m t}\right)^{2} .
$$

The way of obtaining the extremum through multivariate functions is 


$$
\left\{\begin{array}{l}
\frac{\partial Q}{\partial k_{1}}=2\left(k_{1} \sum f_{1 t}^{2}+\cdots+k_{m-1} \sum f_{1 t} f_{(m-1) t}+\cdots\right)=0, \\
\vdots \\
\frac{\partial Q}{\partial k_{m-1}}=2\left(k_{1} \sum f_{1 t} f_{(m-1) t}+\cdots+k_{m-1} \sum f_{(m-1) t}^{2}+\cdots+\sum f_{(m-1) t} f_{m t}\right)=0 .
\end{array}\right.
$$

Equation (5) can be presented as

$$
\left[\begin{array}{cccc}
\sum f_{1 t}^{2} & \sum f_{1 t} f_{2 t} & \cdots & \sum f_{1 t} f_{(m-1) t} \\
\sum f_{1 t} f_{2 t} & \sum f_{2 t}^{2} & \cdots & \sum f_{2 t} f_{(m-1) t} \\
\vdots & \vdots & \vdots & \vdots \\
\sum f_{1 t} f_{(m-1) t} & \sum f_{2 t} f_{(m-1) t} & \cdots & \sum f_{(m-1) t}^{2}
\end{array}\right]\left[\begin{array}{c}
k_{1} \\
k_{2} \\
\vdots \\
k_{m-1}
\end{array}\right]=\left[\begin{array}{c}
\sum f_{1 t} f_{m t} \\
\sum f_{2 t} f_{m t} \\
\vdots \\
\sum f_{m t}^{2}
\end{array}\right] .
$$

Let

$$
\begin{aligned}
D & =\left[\begin{array}{cccc}
f_{11} & \cdots & \cdots & f_{1 n} \\
f_{21} & \cdots & \cdots & f_{2 n} \\
\vdots & \vdots & \vdots & \vdots \\
f_{(m-1) 1} & f_{(m-1) 2} & \cdots & f_{(m-1) n}
\end{array}\right], \\
k & =\left[\begin{array}{c}
k_{1} \\
k_{2} \\
\vdots \\
k_{m-1}
\end{array}\right], \\
F & =\left[\begin{array}{c}
f_{m 1} \\
f_{m 2} \\
\vdots \\
f_{m n}
\end{array}\right] .
\end{aligned}
$$

Then,

$$
D D^{T} K=-D F
$$

Let there be no linear correlation between the above $m$ ways, only $n \geq m-1$; then, $m-1$ rows of vectors are linearly independent, so $D D^{T}$ is reversible; that is, there is a unique solution in the equations, which is the form of equation (4).

As can be observed from the above, there is a unique stagnation point $K=-\left(D D^{T}\right)^{-1} D F$. When $m=2$, the optimal combined coefficients for the two prediction modes are expressed as

$$
\begin{aligned}
& K_{1}=-\frac{\sum f_{1 t} f_{2 t}}{\sum f_{1 t}^{2}}=-\frac{\sum\left(e_{1 t}-e_{2 t}\right) e_{2 t}}{\sum\left(e_{1 t}-e_{2 t}\right)^{2}}=\frac{\sum e_{2 t}^{2}-\sum e_{1 t} e_{2 t}}{\sum e_{1 t}^{2}+\sum e_{2 t}^{2}-2 \sum e_{1 t} e_{2 t}}, \\
& K_{2}=1-K_{1} .
\end{aligned}
$$

By means of the optimal weight coefficient, the linear combination of feature extraction results and rainfall runoff pollution prediction based on feature fusion are realized.

2.3. Prediction of Rainfall Runoff Pollution. It is found from analyzing the characteristics of rainfall runoff pollutions that floating dust, surface debris, and dirt are the main sources of runoff pollutants. Pollutants during rainfall mainly produced the rainfall runoff pollution, which is especially obvious in industrial areas. The rainfall pollutants are composed of two contents: one is the background value of rainfall pollutants being more stable and the other is the wet deposition caused by the atmosphere during rainfall. Ground pollutants are considered as a critical part of runoff pollutants, because the pollutants accumulate in various forms on the impervious areas such as streets, gutters, and drainage systems. The impact of urban sewer transport system on water quality mainly lies in the sewage diffused from sediments and drainage systems, of which the nonpoint source pollution caused by erosion of the sewer at the beginning of rainfall runoff is the main source. This is because the water body remained in the sedimentation pond from previous runoff and the solids are prone to spoilage; the runoff generated during rainfall will take away the sediments and sewage in the sewer.

The main influencing factors of rainfall runoff pollution include precipitation, surface pollutants, and land use. To some extent, the rainfall intensity determines the ability of the ground pollutants; the precipitation determines the amount of diluted pollutants; the rainfall duration determines the time of pollutant erosion and the period of transmitting pollutants to the ground; the type of land use determines the nature and accumulation rate of pollutants; the accumulation of ground pollutants on sunny days will directly affect the runoff pollutions. All these indicate that the factors affecting rainfall runoff pollutions are many and random. 
In summary of the above analysis and calculation, the basic characteristics and main influencing factors of rainfall runoff pollution are obtained. The key to generating rainfall runoff pollution depends on the accumulation of surface pollutions on sunny days and the rainfall erosion, of which the latter is directly correlated with precipitation. That means the erosion phenomenon only occurs when precipitation reaches a certain level, so that the rainfall runoff pollution is formed. The total cumulative amount of surface pollutants is correlated with the cumulative time before rainfall pollution. The methods for simulating the accumulation model of pollutants on sunny days mainly include power function method, exponential function method, and saturation function method. For the power function method, the cumulative pollution amount $B_{T^{\prime}}$ per unit area is calculated according to the following:

$$
B_{T^{\prime}}=\min \left(B_{0}, B_{1} T^{\prime B_{2}}\right),
$$

where $T^{\prime}$ represents the time of pollution accumulation before rainfall, $B_{0}$ represents the maximum pollution cumulative amount per unit area, $B_{1}$ represents the constant of pollution cumulative rate, and $B_{2}$ represents the time index.

The second is the exponential function method, whose equation is

$$
B_{T^{\prime}}=B_{L}+\left(B_{0}-B_{L}\right) \times \exp \left(-B_{1} \times T^{\prime}\right),
$$

where $B_{L}$ represents the amount of pollutions that remained on the surface before the pollution accumulation.

The third is saturation function method, whose equation is

$$
B_{T^{\prime}}=B_{L}+\left(B_{0}-B_{L}\right) \frac{T^{\prime}}{B_{3}+T^{\prime}},
$$

where $B_{3}$ represents the half-saturation constant in the process of pollution accumulation.

In the construction of rainfall pollutant erosion model, the index function method is compared with the calibration curve method. In the exponential function method, the total pollution erosion amount per unit area in unit time $W$ is expressed as

$$
W=K_{1} K_{2} C_{1}^{\prime} q^{C_{2 \prime}} B,
$$

where $C_{1}^{\prime}$ represents erosion coefficient, $C_{2}^{\prime}$ represents erosion index, and $q$ represents total runoff per unit area.

In the calibration curve method, the total pollution erosion amount per unit area in unit time $W$ is expressed as

$$
W=K_{1} K_{2} C_{1}^{\prime} q^{C_{2} \prime} .
$$

The saturation function method of total accumulative pollution on sunny days and the rain erosion exponential function method are calculated and analyzed as an example. Based on equation (13),

$$
\mathrm{d} B=-W \mathrm{~d} t=C_{1}^{\prime} q^{C_{2 \prime}} B \mathrm{~d} t .
$$

To sum up, the concentration values for rainfall runoff pollutants $C^{\prime}$ can be obtained:

$$
\begin{aligned}
C^{\prime}= & C_{0}^{\prime}+\frac{W}{q}=C_{0}^{\prime}+C_{1}^{\prime} q^{C_{2 \prime}-1} B_{T^{\prime}} \exp \left(-C_{1}^{\prime} \int_{0}^{t} q(t)^{C_{2 \prime}} \mathrm{d} t\right) \\
= & C_{0}^{\prime}+C_{1}^{\prime} q^{C_{2 \prime}-1}\left(B_{L}+\left(B_{0}-B_{L}\right) \frac{T^{\prime}}{B_{1}+T^{\prime}}\right) \\
& \times \exp \left(-C_{1}^{\prime} \int_{0}^{t} q(t)^{C_{2 \prime}} \mathrm{d} t\right),
\end{aligned}
$$

where $C_{0}^{\prime}$ represents the total concentration of atmospheric pollutants contained before the falling of raindrops and $q(t)$ represents the function of rainfall runoff generated under time variation.

\section{Experimental Results and Analysis}

The urban non-point source includes the erosion and washing of rainfall runoff. Mainly in the form of confluence system and discharged by drainage system, the rainfall runoff pollution plays a significant role in the initial stage. In the process of verifying the rainfall runoff pollution prediction method based on the grey neural network algorithm, the corresponding analysis and calculation are performed after a typical heavy rain, and the experimental platform is built on Mathematica. Figure 2 shows the process curve of rainstorm. Figure 3 presents the results of simulating the whole process of rainstorm runoff in the confluence area, the pollution factors, and indicators under urban non-point source pollution. In order to reduce the experiment complexity, the fitting between the actual situation and the predicted SS as well as COD pollution values is taken as the representative to verify the accuracy of proposed method.

Due to the poor water permeability at water-logged area with relatively large rainfall runoff coefficient, the rainfall runoff is formed quickly and the total runoff at initial stage increases dramatically, reaching the peak in a relatively short period of time. The overall changes of SS and COD are basically the same. The calculated values of water volume and quality are roughly consistent with the actual amount with strong fitting. The calculated error in water quality, that is, the predicted value of rainfall runoff pollution concentration, is small, and the accuracy can meet the actual engineering demands.

For the sake of verifying the practicability of the proposed method, the experiment was carried out in a specific simulation scenario on the test platform. First, the pre-rain drought period in the water quality simulation hypothesis area was set at 8 days, the accumulated rainfall was set at $72 \mathrm{~mm}, 120 \mathrm{~min}$ of rainfall duration was set as the standard parameter, and the annual rainfall was set at $1875.4 \mathrm{~mm}$. For the evaporation amount, solar radiation, and cloud cover, the real-time data of the National Meteorological Observatory was taken as the reference. The specific pollutant calculation formula is shown in Table 1. 


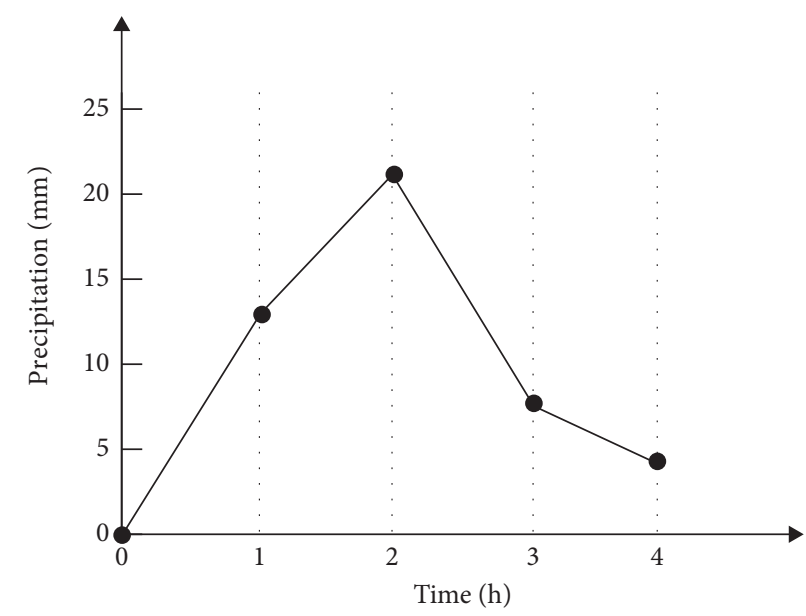

FIGURE 2: Diagram of rainstorm process curve.

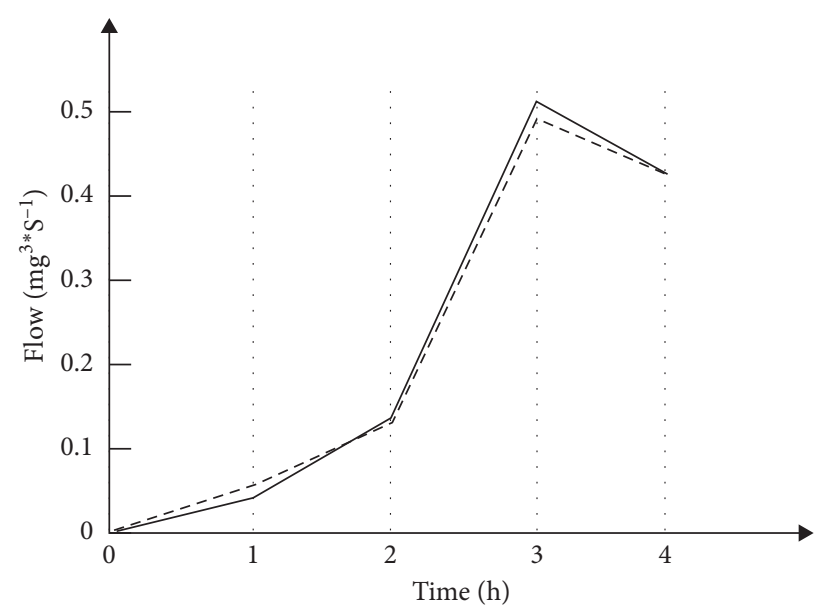

_- Actual value _. - Predictive value

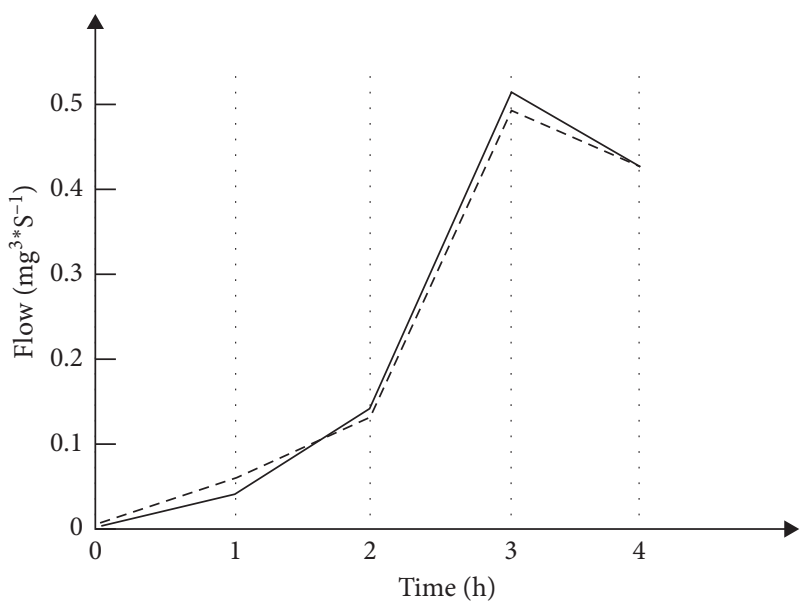

- Actual value _. _ Predictive value

(a)

(b)

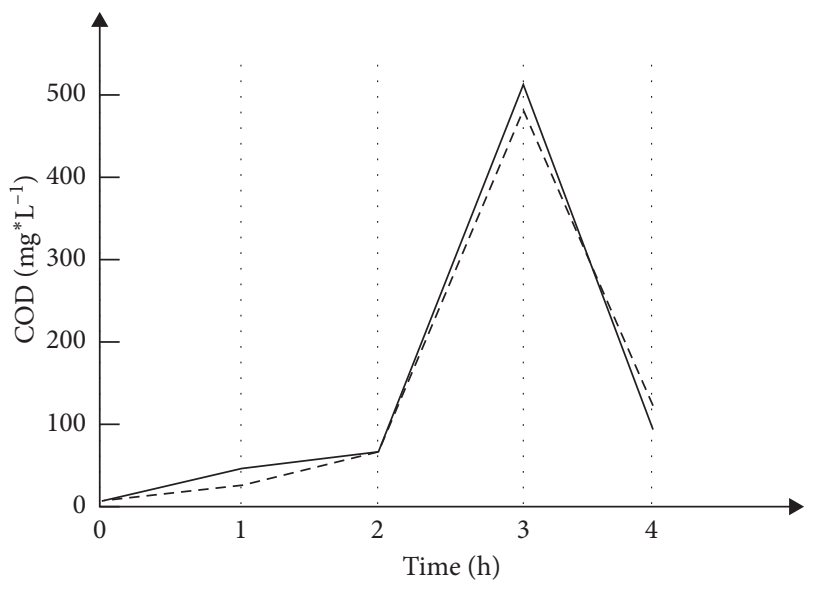

- Actual value

- - - Predictive value

(c)

FIGURE 3: Results of rainfall runoff pollution prediction based on grey neural network algorithm. (a) Predicted flow value and fitting with actual value, (b) predicted SS concentration value and fitting with actual value, (c) predicted COD concentration value and fitting with actual value. 
TABLE 1: Calculation formula for five pollutants.

\begin{tabular}{lcc}
\hline Contaminant & Formula & $R^{2}$ \\
\hline $\mathrm{TN}$ & $y=0.7646 x-0.8886$ & 0.9971 \\
$\mathrm{TP}$ & $y=0.1602 x$ & 0.9708 \\
$\mathrm{COD}$ & $y=10.879 x+9.8454$ & 0.9869 \\
$\mathrm{SS}$ & $y=71.488 x$ & 0.9538 \\
$\mathrm{NH}_{3}-\mathrm{N}$ & $y=0.362 x$ & 0.9707 \\
\hline
\end{tabular}

The variation range of the above five pollutants is collected as the accumulated pollution. Under the abovementioned scenario, the continuous increase of precipitation triggers the increase of runoff amount. Meanwhile, comparative test is carried out by predicting the accumulated pollution load. Figure 4 shows the results of comparing the experimental results with the prediction methods in literature.

According to Figures 4 and 5, in the prediction curve of the accumulated pollution load based on the proposed method, with the increase of accumulated runoff, the higher predicted cumulative pollution load can be reached under the condition of less accumulated runoff, which explains that the proposed method can prevent the loss of effective and available information. Although the designed rainfall only starts from the rainfall event control rate without giving consideration to the specific water quality conditions, the above pollution load will be affected by the original water quality since the concentration of runoff pollutants will usually decrease in the latter stage. However, all of the three prediction methods are conducted in the same parameter setting, indicating that the proposed prediction method not only overcomes the limitations of single prediction model but also improves the accuracy of rainfall runoff pollution prediction and enhances the practicability as well as robustness.

\section{Suggestions on Pollution Control}

After a long time study and exploration of measures for treating the runoff pollution, developed countries have designed and developed systematic control as well as technical system. Among them, the engineering and nonengineering measures are most representative. The following is the analysis of these two measures, respectively.

4.1. Non-Engineering Measures. With the focuses on the source of control, the natural and ecological governance options, and non-engineering approaches, these measures intend to achieve ecological pollution control through the enhanced management. The detailed plans include the prevention and control via diversion system, increase of urban greening area, cleaning of sewage pipeline system, waste sorting, reduction of garbage dumping, efficient management of construction site and machinery repair plant, and scientific control of urban greenfield fertilization and pesticide use. In addition to formulating the reasonable policies, it is also necessary to strengthen the publicity and education on public ecological environmental protection.

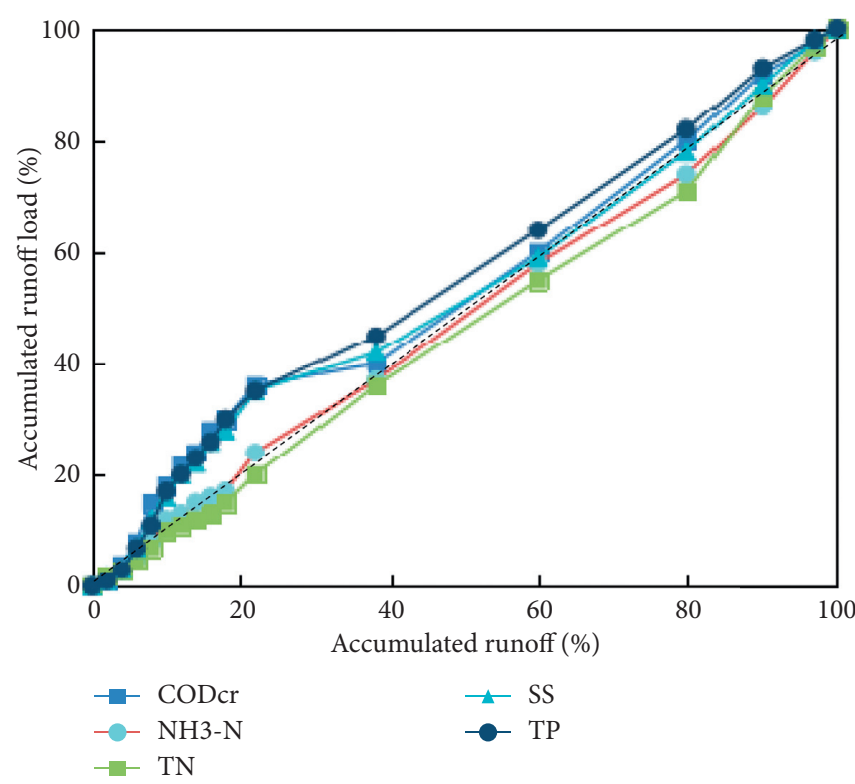

Figure 4: Prediction results of real-time pollution simulation through the proposed method.

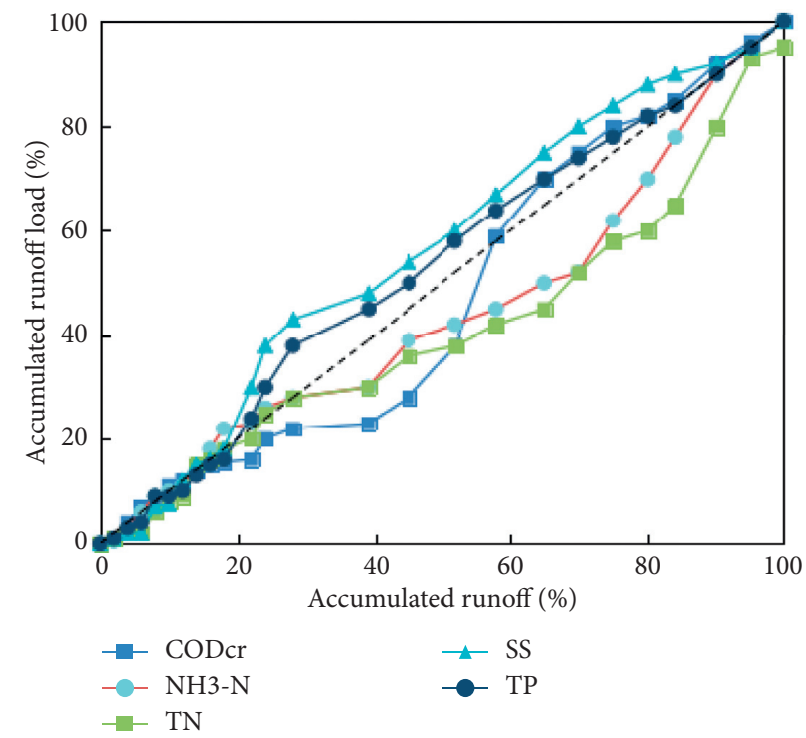

Figure 5: Prediction results of real-time pollution simulation through methods in the literature.

4.2. Engineering Measures. The source control shall not only cover management measures, that is, non-engineering measures, but also focus on the measures for reducing heavy pollutants in runoff. Street runoff usually flows directly into the drainage network system, so it is of great significance in reducing and controlling the pollutants by selecting the appropriate gullies, such as applying the water quality-based gullies to filter out various sediments and oils in road runoff. In regard to the control of the runoff of community road surface, it is suggested to increase the community green area and enhance the water permeability and then collect and simply process the internal runoff for watering green space and spraying road surface. Considering that the roof runoff 
pollution is affected by dust and roofing materials, the green space or artificial soil layer may be utilized to penetrate underground, so as to reduce rainfall runoff pollution in urban areas.

By means of adopting appropriate treatment programs based on the basic principle of rainfall runoff pollution transmission and diffusion, the discharge of pollutants into underground or surface water bodies can be efficiently reduced. For the precipitation runoff that does not flow into the sewer, the forest grass buffer area may be constructed through natural channels and constructed wetlands so as to significantly reduce the total amount of pollutants in transit. Because the drainage system in urban areas is one of the key approaches to spread pollution, the planning and control of rainwater pipelines shall be effectively integrated with the urban runoff source control system as well as the terminal treatment system.

The old drainage systems in many domestic cities adopt the combined system, which means that the rainwater and sewage are parallel to the drainage pipe. As a result, the normal treatment of the sewage will be seriously affected due to the high fluctuation of rainwater, so the straight drainage often occurs in combined pipelines. The intercept combined drainage system is usually applied in the process of optimizing the old combined flow system, which can transfer the initial rainwater and street waste water to the sewage treatment plant. The diversion system is superior to the combined system in terms of operational performance, so it is generally adopted in China's new urban areas.

The above-mentioned terminal treatment means achieving effective degradation of runoff pollutants by utilizing natural ecological technology or artificial purification technology. The main measures include rainwater regulation tanks, storage ponds, and constructed wetlands. Among them, the load of various pollutants in the water storage pond is very high, but the pond can form an ecosystem based on the contained floating matter and aquatic plants to degrade and digest various pollutants in the runoff, thereby improving the water storage in the pond and optimizing the overall ecological environment around. Rainwater regulation tank is a widely used rainfall runoff pollution control solution, which can effectively prevent and control rainfall runoff pollution through physical, chemical, and biological methods. The rainwater regulation tank is generally composed of a water storage tank and a sedimentation tank, where the former is usually added subsequently for recycling.

\section{Conclusions}

A rainfall runoff pollution prediction method based on feature fusion is proposed for the prediction and treatment of rainfall runoff pollution. On the basis of analysis, the characteristics of rainfall runoff pollution are extracted through combining with the grey algorithm and neural network method, which are further organically integrated via feature fusion so as to construct a model of rainfall runoff pollution prediction. As proved by the experiment, the proposed method can effectively predict runoff pollution with good fitting between the predicted value and the actual value. For the sake of better strengthening the urban ecological construction and providing a reliable basis for nonpoint source pollution control, the rainfall runoff pollution process will be simulated, and the performance of the proposed method will be further verified via different rain types.

\section{Data Availability}

All data are available upon request to the corresponding author.

\section{Conflicts of Interest}

The authors declare that they have no conflicts of interest.

\section{References}

[1] Y. Luo, K. Yang, Z. Yu et al., "Dynamic monitoring and prediction of dianchi lake cyanobacteria outbreaks in the context of rapid urbanization," Environmental Science and Pollution Research, vol. 24, no. 6, pp. 5335-5348, 2016.

[2] A. Zmy, B. S. Mo, and B Shen, "An enhanced extreme learning machine model for river flow forecasting: state-of-the-art, practical applications in water resource engineering area and future research direction," Journal of Hydrology, vol. 569, pp. 387-408, 2019.

[3] I. Iskender and N. Sajikumar, "Evaluation of surface runoff estimation in ungauged watersheds using SWAT and GIUH," Procedia Technology, vol. 24, pp. 109-115, 2016.

[4] L. Chen, C. Sun, G. Wang, H. Xie, and Z. Shen, "Event-based nonpoint source pollution prediction in a scarce data catchment," Journal of Hydrology, vol. 552, pp. 13-27, 2017.

[5] X. Li, H. R. Maier, and A. C. Zecchin, "Improved pmi-based input variable selection approach for artificial neural network and other data driven environmental and water resource models," Environmental Modelling \& Software, vol. 65, pp. 15-29, 2015.

[6] N. V. Bhattacharjee and E. W. Tollner, "Improving management of windrow composting systems by modeling runoff water quality dynamics using recurrent neural network," Ecological Modelling, vol. 339, pp. 68-76, 2016.

[7] M. A. Paule-Mercado, J. S. Ventura, S. A. Memon, D. Jahng, J.-H. Kang, and C.-H. Lee, "Monitoring and predicting the fecal indicator bacteria concentrations from agricultural, mixed land use and urban stormwater runoff," Science of The Total Environment, vol. 550, pp. 1171-1181, 2016.

[8] K. Chinen, S.-L. Lau, M. Nonezyan et al., "Predicting runoff induced mass loads in urban watersheds: linking land use and pyrethroid contamination," Water Research, vol. 102, pp. 607-618, 2016.

[9] A. K. Kadam, V. M. Wagh, A. A. Muley, B. N. Umrikar, and R. N. Sankhua, "Prediction of water quality index using artificial neural network and multiple linear regression modelling approach in Shivganga River basin, India," Modeling Earth Systems and Environment, vol. 5, no. 3, pp. 951-962, 2019.

[10] A. Elzwayie, A. El-Shafie, Z. M. Yaseen, H. A. Afan, and M. F. Allawi, "RBFNN-based model for heavy metal prediction for different climatic and pollution conditions," Neural Computing \& Applications, vol. 28, no. 8, pp. 1-13, 2017. 
[11] L. Bo, Z. Yi-Fan, Z. Bei-Bei, and W. Xian-Qing, "A risk evaluation model for karst groundwater pollution based on geographic information system and artificial neural network applications," Environmental Geology, vol. 77, no. 9, pp. 341-344, 2018.

[12] L. Qian, J. Li, C. Liu, J. Tao, and F. Chen, "River flow sequence feature extraction and prediction using an enhanced sparse autoencoder," Journal of Hydroinformatics, vol. 22, no. 5, pp. 1391-1409, 2020.

[13] P. Zhang, Y. Cai, and J. Wang, "A simulation-based real-time control system for reducing urban runoff pollution through a stormwater storage tank," Journal of Cleaner Production, vol. 183, pp. 641-652, 2018.

[14] S. Thorndahl and M. R. Rasmussen, "Short-term forecasting of urban storm water runoff in real-time using extrapolated radar rainfall data," Journal of Hydroinformatics, vol. 15, no. 3, pp. 897-912, 2013.

[15] X. X. Sun, S. H. Mo, B. Shen, M. Liu, and Y. J. Li, "Runoff predicting model based on improved Markov chain," Journal of Shenyang Agricultural University, vol. 37, no. 6, pp. 872877, 2006.

[16] Y. Zheng, X. Luo, W. Zhang et al., "Enrichment behavior and transport mechanism of soil-bound PAHs during rainfallrunoff events," Environmental Pollution, vol. 171, pp. 85-92, 2012. 